\title{
Probing the Impact of Solvent on Lewis Acid Catalysis via Fluorescent Lewis Adducts
}

Amy E. Laturski, Jordan N. Bentley, Joshua R. Gaffen, Christopher B. Caputo*, and Thomas Baumgartner*

Department of Chemistry, York University, 4700 Keele Street, Toronto, ON M3J 1P3, Canada

KEYWORDS: Lewis acid, fluorescent Lewis adduct, solvents, catalysis

\section{ABSTRACT}

Over the years, various multiparameter methods have been developed to measure the strength of a Lewis acid. However, a major challenge for these measurements lies in the complexity that arises from variables such as solvent and other fundamental interactions, as well as perturbations of Lewis acids as their reaction environment changes. Herein, we evaluate the impact of solvent effects on the Fluorescent Lewis Adduct (FLA) method using a series of representative Lewis acids. The solution-state nature of the FLA method in particular offers the ability to correlate Lewis Acid Units (LAUs) obtained from the FLA measurement with reactivity. The binding of a Lewis acid in various solvents reveals a measurable dichotomy between both polarity and donor ability of the solvent. While not strictly separable, as solvent polarity increases observed LAUs increase; however, as solvent donor ability increases the observed LAUs decrease. This dichotomy was confirmed by titration data and catalytic Diels-Alder cycloaddition and hydrosilylation reactions 
with neutral boranes, illustrating that solvation effects can be appropriately gauged by LAU value determined from the FLA method.

\section{INTRODUCTION}

Lewis acids have become essential throughout the chemical sciences, particularly in the field of catalysis, ${ }^{1-3}$ and organoelectronics. ${ }^{4-6}$ The field of catalysis, in particular, has seen great benefit from the emergence of frustrated Lewis pairs (FLP) and metal-free catalysis., ${ }^{2,-9}$ As Lewis acid chemistry begins to permeate other disciplines, the need for correlating the acceptor strength of a Lewis acid with their efficacies in their proposed application becomes vital. However, determining the specific reactivity of Lewis acids remains ambiguous, creating challenges in selecting an appropriate Lewis acid to achieve a desired reaction. ${ }^{1}$ Currently, Lewis acidity cannot be described by a single measured property, and several parameters must be considered jointly in order to select a potent Lewis acid catalyst. ${ }^{10-12}$ As such, multiparameter models based on spectroscopic and computational methods have been developed to quantitatively distinguish Lewis acidity, such as, the Gutmann-Beckett method, the Childs method, ion affinity, and the global electrophilicity index (Scheme 1). However, these approaches may sometimes lead to inconclusive results depending on the applied method. ${ }^{13-18}$

Thus, we recently established a new methodology based on fluorescence spectroscopy to enumerate Lewis acidity, termed Fluorescent Lewis Adduct (FLA). ${ }^{19,20}$ This method derives a basis for Lewis acidity by utilizing a series of fluorescent dithieno[3,2-b:2', $\left.3^{\prime}-d\right]$ phosphole oxide Lewis base probes ${ }^{21-23}$ that, when bound to a Lewis acid in solution, undergo a bathochromic shift with their optical properties (Scheme 1). ${ }^{19}$ 
Gutmann-Beckett:<smiles>CCP(=O)(CC)CC</smiles>

downfield ${ }^{31} \mathrm{P}$ NMR resonance

Childs:

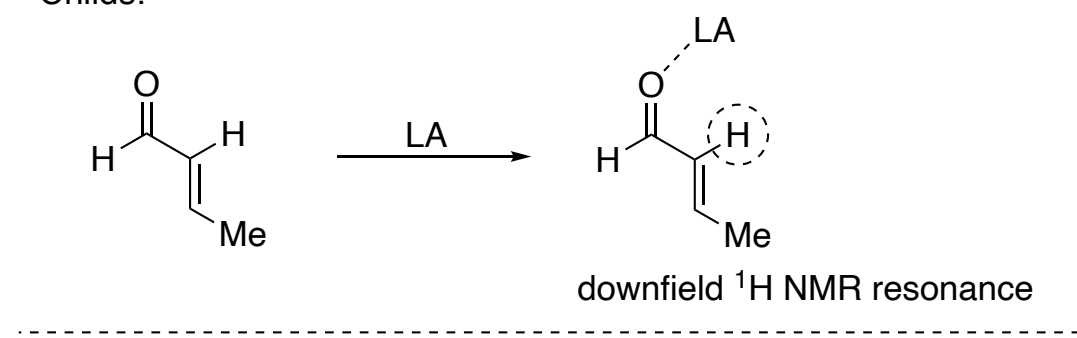

Ion Affinity:

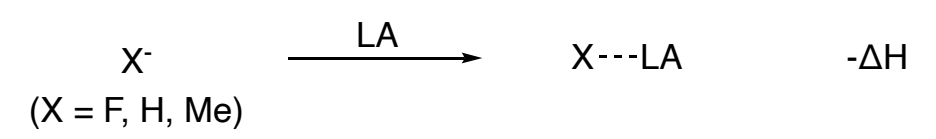

Global Electrophilicity Index (GEI):

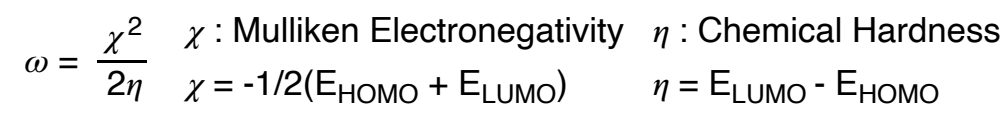

Fluorescent Lewis Adduct (FLA):
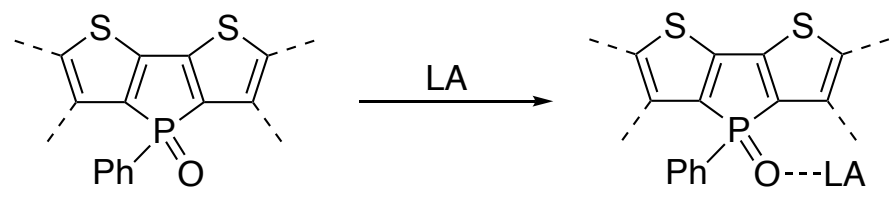

red-shifted emission

Scheme 1. Multiparameter models for measuring Lewis acidity (LA = Lewis acid).

The degree of the bathochromic shift is generally proportional to the Lewis acid strength, as our method is based on the fact that Lewis-acid coordination alters the polarity of the exocyclic $\mathrm{P}=\mathrm{O}$ bond with direct implications toward a lowered LUMO energy level, i.e., the $\pi^{*}$-system of the probe. ${ }^{19,24}$ Similarly, by utilizing chromaticity, we incorporate a broad range of outer-sphere electronic permutations, allowing for a true "solution-state" measure, i.e., one that is more 
consistent with the nature of the Lewis acid in solution than simply the measure of the impact to a 'naked' Lewis base itself.

The FLA method differs from typical Lewis-acid measurements in that it leverages the impact of the Lewis acid on several Lewis bases to determine the binding with an "ideal" Lewis base. ${ }^{19,20}$ This affords the system high versatility, while the use of fluorescence and chromaticity specifically, affords a high sensitivity. Similarly, as this method can theoretically be performed in any solution, we refer to it as a "solution-state measurement". As long as the Lewis acid is not independently fluorescent, the FLA method provides the opportunity to gain important insight into the characteristics and reactivity of Lewis acids. Our initial proof-of-concept for the FLA method demonstrated its simplicity and sensitivity, ${ }^{19}$ whereas in our most recent paper, the robustness and broad scope was highlighted by expanding our library of measured Lewis acids to over 50 species, including both common and unique compounds that could not be measured by pre-existing methods. ${ }^{20}$ These foundational contributions have provided a considerable step forward in developing the FLA method, allowing us to explore a variety of inherently dissimilar Lewis acids in an otherwise identical chemical environment. This approach provides a means for determining the effective Lewis acidity of a species in any given environment. Previously, the FLA method had been solely performed in toluene for its benign reactivity and the sufficient solvation of our probes and the many measured substrates. However, to provide true utility, we surmised that our method must also show robustness across varied chemical environments.

The solution-state measurements of the FLA method afford us the potential to measure how Lewis acids may differ under environmental changes, such as in the presence of additional donor species (including solvents) or varied polarity. We envisioned this to provide insight into the effectiveness of these Lewis acids in specific reaction environments and to allow us to correlate 
the FLA measurement directly to catalytic efficacy in chemical reactions. ${ }^{25,26}$ We now report the impact of solvent effects in the FLA method, showcasing the variability of Lewis acidity of a series of species due to different solvent environments. Furthermore, our methodology provides insight into additional aspects of Lewis-acid-catalyzed reactions and highlights some of the fundamental interactions and perturbations of Lewis acids as their reaction environment changes.

\section{RESULTS AND DISCUSSION}

Establishing the Impact of Solvent on the FLA Method

The FLA method utilizes multiple probes whose emission chromaticities span the commission international de l'éclairage (CIE) diagram (Figure 1). ${ }^{20}$ In the context of this study, four probes $(\mathbf{1}, \mathbf{2}, \mathbf{7}$, and $\mathbf{8})$ were used to measure their respective emission profiles in varying polar solvents. ${ }^{21-}$

${ }^{23}$ The selected solvents ranged in polarity from non-polar to polar based on the Dimroth-Reichardt $\mathrm{E}_{\mathrm{T}}(30)$ parameter; toluene $(\mathrm{Tol}, 33.9 \mathrm{kcal} / \mathrm{mol})$, diethyl ether $\left(\mathrm{Et}_{2} \mathrm{O}, 34.6 \mathrm{kcal} / \mathrm{mol}\right)$, chlorobenzene $(\mathrm{PhCl}, 37.5 \mathrm{kcal} / \mathrm{mol})$, dichloromethane (DCM, $41.1 \mathrm{kcal} / \mathrm{mol})$, and acetonitrile $(\mathrm{MeCN}, 46.0$ $\mathrm{kcal} / \mathrm{mol}) .{ }^{27}$ Notably, the polarity of the respective solvents was found to by and large not affect the emissions of the probes (Figure S1). The lack of any notable solvatochromism with the Lewis base probes in the varying polar solvents enabled us to infer that any observed solvatochromism within the FLA method would be owed to the Lewis adduct formation. 


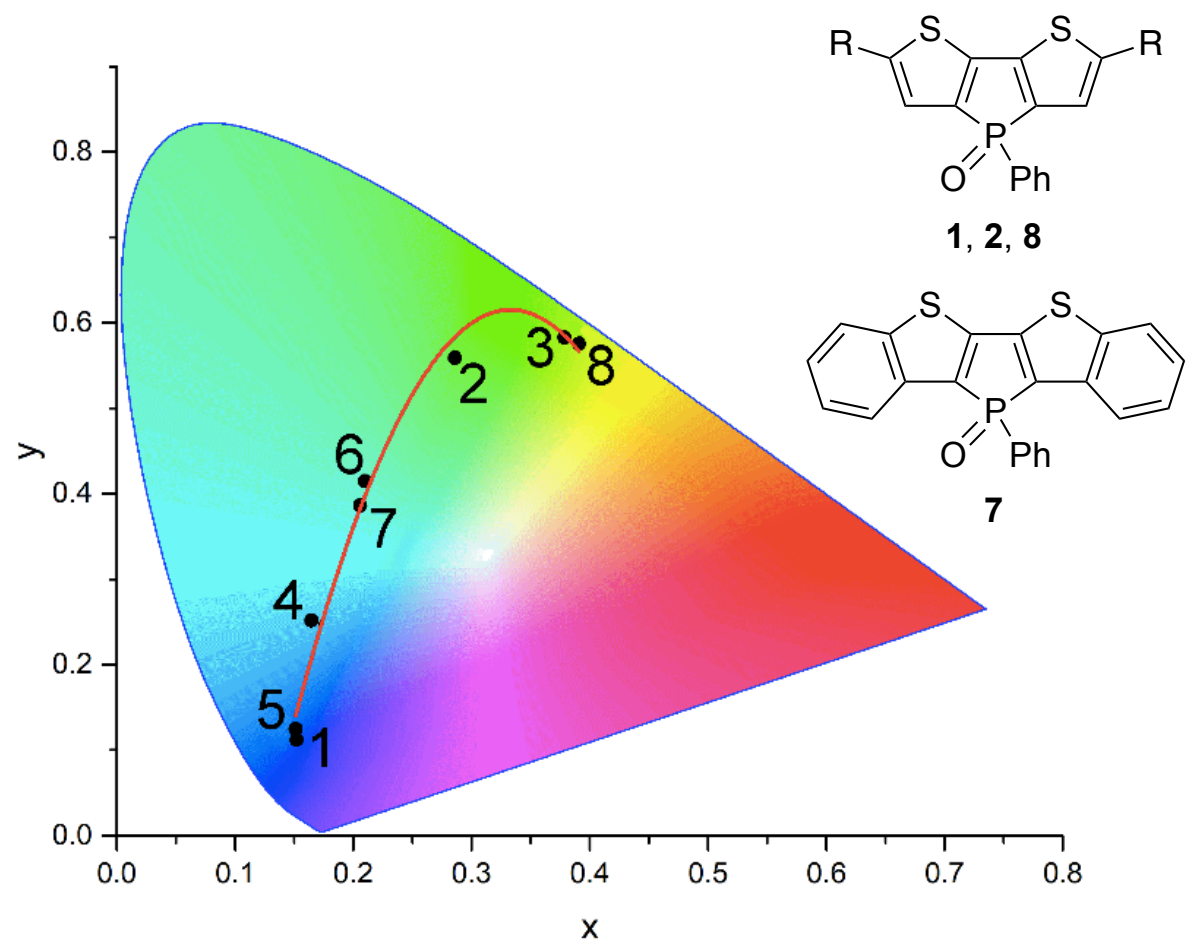

Figure 1. CIE diagram overlaid with the parabolic fit in toluene for eight dithienophosphole probes. ${ }^{20}$ Probes $\mathbf{1}, \mathbf{2}, \mathbf{7}$, and $\mathbf{8}$ were utilized in this study $(\mathbf{1}: \mathrm{R}=\mathrm{H} ; \mathbf{2}: \mathrm{R}=\mathrm{Ph}, \mathbf{8}: \mathrm{R}=2$-thienyl).

To explore the impact of solvent effects in the FLA method, we first selected $\mathrm{B}\left(\mathrm{C}_{6} \mathrm{~F}_{5}\right)_{3}$ as a representative Lewis acid due to its notoriety, as well as having generally served as a reference throughout our studies. Using our previously reported procedure ${ }^{20}$ the Lewis acid unit (LAU) values for $\mathrm{B}\left(\mathrm{C}_{6} \mathrm{~F}_{5}\right)_{3}$ in the various solvents were determined. In general, we observe increasing LAU values relative to the solvent polarity, as shown in Figure 2 and Table S1. However, we also observed that the donor potential of the solvent can lower the LAU value as seen with $\mathrm{Et}_{2} \mathrm{O}$; utilizing a stronger donating solvent can allow for a more rapid generation of solvates, which limits the formation of the fluorescent Lewis adduct. For example, $\mathrm{MeCN}$ precluded formation of the FLA adduct with $\mathrm{B}\left(\mathrm{C}_{6} \mathrm{~F}_{5}\right)_{3}$ entirely, even with a large excess of Lewis acid, due to the strong Lewis acid-base adduct formed between the solvent and $\mathrm{B}\left(\mathrm{C}_{6} \mathrm{~F}_{5}\right)_{3} .{ }^{28}$ To compare the donor potential of 
the solvents chosen, we refer to the donor number introduced by Gutmann et al., defined as the negative reaction enthalpy for the 1:1 adduct formation between the standard Lewis acid, $\mathrm{SbCl}_{5}$, and the electron pair donor (EPD) solvents in 1,2-dichloroethane $(0 \mathrm{kcal} / \mathrm{mol}) .{ }^{29}$ The donor number measures the ability of a solvent to solvate the standard Lewis acid, the selected solvents used in this report ranged in donor ability from non-coordinating to coordinating; toluene (Tol, 0.1 $\mathrm{kcal} / \mathrm{mol}$ ), dichloromethane (DCM, $1.0 \mathrm{kcal} / \mathrm{mol})$, chlorobenzene ( $\mathrm{PhCl}, 3.0 \mathrm{kcal} / \mathrm{mol})$, acetonitrile $(\mathrm{MeCN}, 14.1 \mathrm{kcal} / \mathrm{mol})$, and diethyl ether $\left(\mathrm{Et}_{2} \mathrm{O}, 19.2 \mathrm{kcal} / \mathrm{mol}\right) .{ }^{29}$

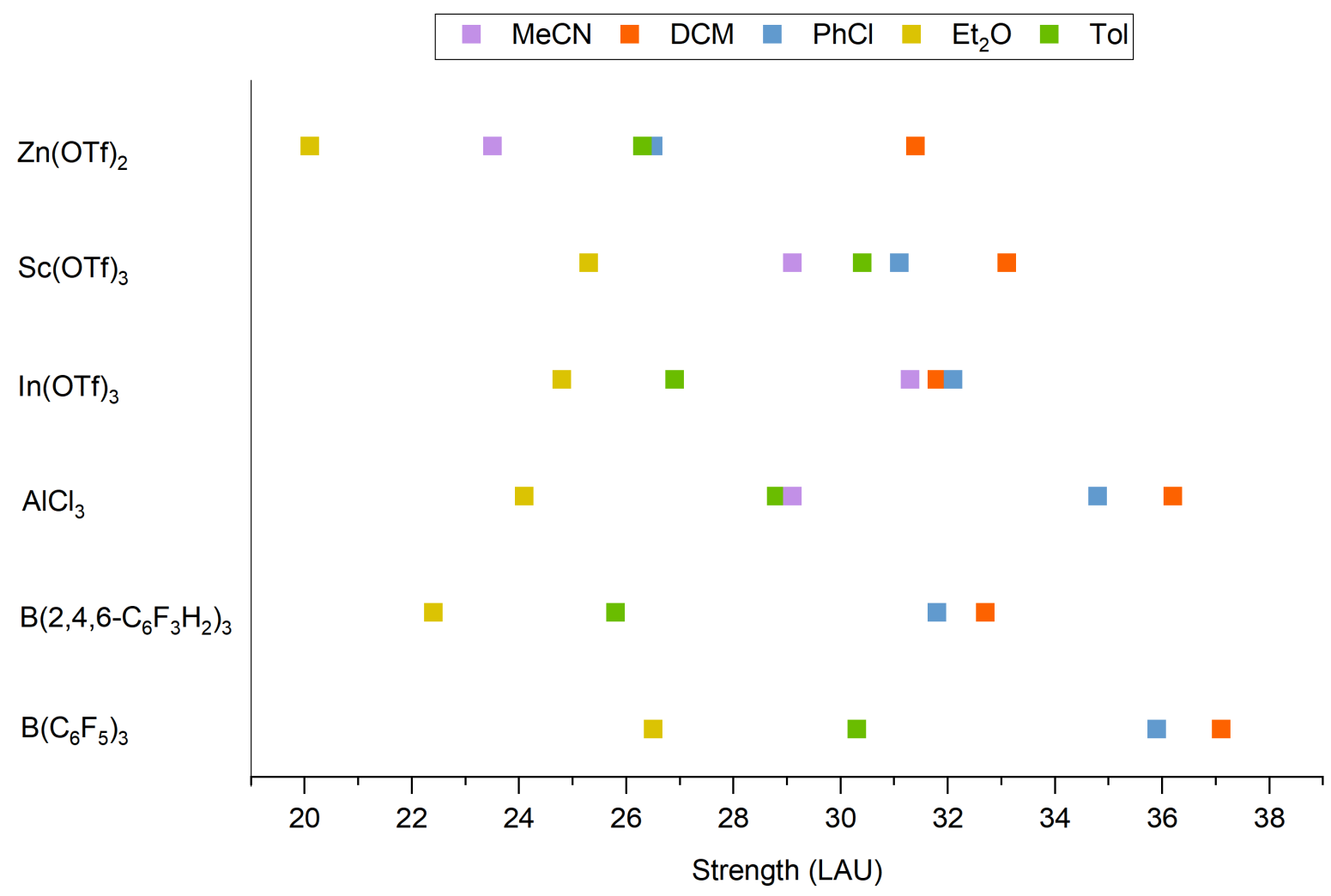

Figure 2. Lewis-acidity scale (in Lewis acid units, $\mathrm{LAU}$ ) for: $\mathrm{B}\left(\mathrm{C}_{6} \mathrm{~F}_{5}\right)_{3}, \mathrm{~B}\left(2,4,6-\mathrm{C}_{6} \mathrm{~F}_{3} \mathrm{H}_{2}\right)_{3}, \mathrm{AlCl}_{3}$, $\mathrm{In}(\mathrm{OTf})_{3}, \mathrm{Sc}(\mathrm{OTf})_{3}$, and, $\mathrm{Zn}(\mathrm{OTf})_{2}$ in varying polar solvents.

To further elaborate the observed relationship between the FLA adduct and solvent in terms of polarity and donor potential, titration studies of $\mathrm{B}\left(\mathrm{C}_{6} \mathrm{~F}_{5}\right)_{3}$ against the probes were conducted in the 
various solvents. ${ }^{30}$ The binding constants were determined from the concentration and the ratio of emission intensities of the adduct and the dithienophosphole oxide at equilibrium on the basis of Equation S1, and are presented in Table S7. ${ }^{30}$ In toluene, the binding constant of probe $\mathbf{1}$ with $\mathrm{B}\left(\mathrm{C}_{6} \mathrm{~F}_{5}\right)_{3}$ was relatively large, $1 \times 10^{5} \mathrm{M}^{-1}$, suggesting a strong interaction between the phosphoryl oxygen atom and the boron center. Upon introducing weakly coordinating solvents, such as DCM and $\mathrm{PhCl}$, the binding constant lowered by nearly an order of magnitude, $\sim 3 \times 10^{4} \mathrm{M}^{-1}$. In $\mathrm{MeCN}$, however, no fluorescent Lewis adduct was formed and thus a binding constant could not be measured. As anticipated, the stronger the coordinating solvent, the weaker the binding constant and $\mathrm{LAU}$ value. For example, $\mathrm{B}\left(\mathrm{C}_{6} \mathrm{~F}_{5}\right)_{3}$ presented an $\mathrm{LAU}$ of 37.10 in $\mathrm{DCM}, 26.50$ in $\mathrm{Et}_{2} \mathrm{O}$ and was unmeasurable in $\mathrm{MeCN}$. These results imply that the interaction between the Lewis-acid and Lewis-base probe becomes less prevalent in polar coordinating solvents. Polar solvents increase the effective Lewis-acid strength in solution, while strong donor solvents reduce or even quench the effective Lewis-acid strength by competing with binding to the Lewis acid. This dichotomy displays the complexity of Lewis acids, and the choice of solvent, an intuitive statement that our method appropriately demonstrates in measurable terms.

Titration experiments in diethyl ether, specifically, afforded an intriguing perspective that arises from this dichotomy. Originally appearing anomalous, in the moderately donating solvent, a clear two-step equilibrium process was observed (Figure S131). Since, our FLA method consists of three components: a Lewis acid, a Lewis base, and the solvent, ${ }^{19}$ it is reasonable to propose that the interactions we observe are the difference in the binding of a free Lewis acid, and a solvated Lewis acid with the Lewis basic probe (Scheme 2). ${ }^{31}$ The two-step equilibrium process was easily observed in the titration curves as two distinctly separate equilibria, specifically when utilizing the relatively weaker Lewis base $(\mathbf{8}) \cdot{ }^{19,20}$ Upon increasing the relative donor strength of the 
dithienophosphole probe (via modification of the conjugated backbone), the rate of (a) increases (Scheme 2), resulting in an overlap in the measure of the two competing equilibria. Thus, utilizing the relatively strongest Lewis base probe $\mathbf{1},{ }^{19,20}$ it becomes unclear as to the distinction between the two equilibria in the titration data. Although the competing reaction is occurring in solution, the rates have become so similar that they are nearly impossible to separate experimentally (Figure S131). These competing equilibria likely occur with other Lewis acids and solvent combinations; however, it may not be feasible to separate them.

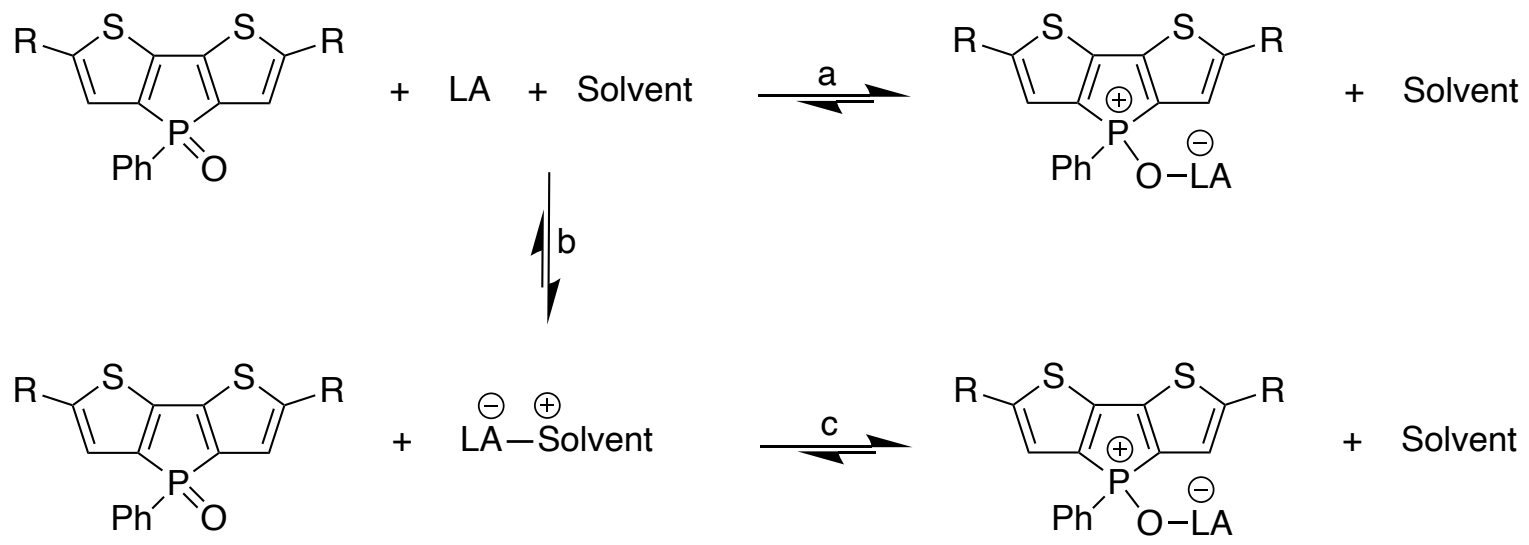

Scheme 2. Proposed competing equilibria during the formation of the fluorescent Lewis adduct (FLA). A stronger Lewis base (i.e., $\mathrm{P}=\mathrm{O}$ ) increases the forward rate of (a), while a stronger donor solvent (acetonitrile) increases the forward rate of (b). With a mild Lewis base and a mildly coordinating solvent such as $\mathrm{Et}_{2} \mathrm{O}$, (a) and (c) can both be seen and measured independently in part due to the slow rate of (b).

This preliminary study conducted with $\mathrm{B}\left(\mathrm{C}_{6} \mathrm{~F}_{5}\right)_{3}$ in the varying polar solvents shed light on the dichotomy seen in the solvent properties of the FLA method. To further expand the scope on the variation of our methodology with respect to solvent effects, the following five representative Lewis acids were chosen based on their utility in catalysis: $\mathrm{AlCl}_{3}, \mathrm{~B}\left(2,4,6-\mathrm{C}_{6} \mathrm{~F}_{3} \mathrm{H}_{2}\right)_{3}, \mathrm{In}(\mathrm{OTf})_{3}$, 
$\mathrm{Sc}(\mathrm{OTf})_{3}$ and $\mathrm{Zn}(\mathrm{OTf})_{2} \cdot{ }^{19,32-37}$ The LAU values of these five Lewis acids were again determined using our previously reported procedure ${ }^{20}$ and we observed the same trends as seen with $\mathrm{B}\left(\mathrm{C}_{6} \mathrm{~F}_{5}\right)_{3}$ in the different solvents. LAU values were generally found to proportionally increase relative to the polarity of the respective solvent, as shown in Figure 2 and Table S1, whereas lower LAU values were observed with stronger donating solvents. As previously stated, these donating solvents allow for a more rapid generation of solvates, which limits the formation of the fluorescent Lewis adduct. The trends seen in the LAU values for these five different Lewis acids are consistent with the observed dichotomy seen in the titration studies with $\mathrm{B}\left(\mathrm{C}_{6} \mathrm{~F}_{5}\right)_{3}$. Thus, summarizing the impact of solvent on the LAU scale, we observe two key, yet not mutually exclusive, factors influencing measured Lewis acidity, the polarity and donating potential of the solvent. ${ }^{27}$ However, due to the solution-state nature of our methodology, we propose that this distinction allows for an improved ability to determine the activity of a Lewis acid in a reaction based on solvent, potentially correlating the FLA measurements directly with catalytic reactions.

\section{Validating the LAU Scale through Chemical Reactivity}

The solvent study confirmed that the FLA method can measure the variance of a Lewis acid's acceptor ability in different environments, even those in which a competing equilibrium is occurring. To determine the value of this observation and the predictive potential of an LAU value with regard to chemical reactivity, we performed two Lewis-acid-catalyzed reactions to interpolate any correlation between catalytic activity and the FLA scale: Diels-Alder cycloaddition of 2,3dimethyl-1,3-butadiene with methyl acrylate, ${ }^{38}$ and hydrosilylation of benzophenone (Scheme 3). ${ }^{39}$ These two reaction types are well established in the literature and are commonly used as representative examples in exploring Lewis acid catalysis. The progression of these reactions 
catalyzed by the same Lewis acids were monitored by ${ }^{1} \mathrm{H}$ NMR spectroscopy in the respective solvents.

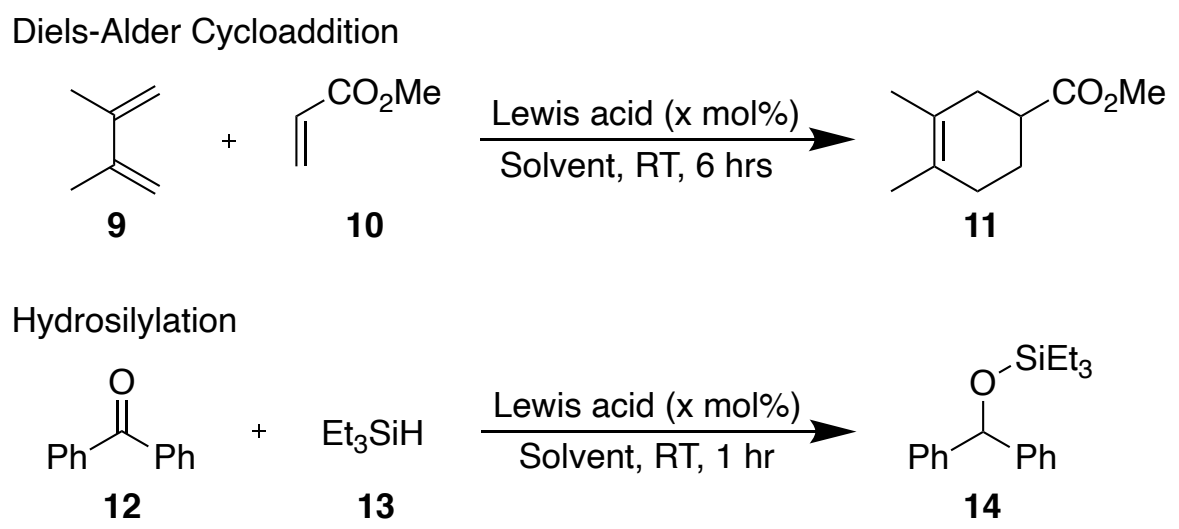

Scheme 3. The two representative Lewis-acid-catalyzed reactions used to interpolate any correlation between catalytic activity and the FLA method.

For the set of Diels-Alder cycloadditions, 2,3-dimethyl-1,3-butadiene (9) and methyl acrylate (10) were the chosen substrate combination to form the resultant methyl-3,4-dimethyl-3cyclohexenecarboxylate (11). In the presence of $5 \mathrm{~mol} \% \mathrm{AlCl}_{3}$, (Table $\mathbf{S 8}$ ), the reaction was significantly impacted by varying the solvent. The change in polarity of the solvent clearly altered the progress of the reaction, as exemplified in Figure $\mathbf{3 A}$. Matching well with the results of the titration experiments, the reaction in a more polar solvent progressed at a faster rate with a higher product conversion over 4 hours, while the coordinating ability of the solvent negatively influenced the progress of the reaction, demonstrated by a slower and lower product conversion over the same time frame. The results of $\mathrm{AlCl}_{3}$ are as follows: $\mathrm{DCM}(87 \%, 36.15 \mathrm{LAU}), \mathrm{PhCl}$ (85\%, 34.79 LAU), Tol (84\%, 28.89 LAU), $\mathrm{Et}_{2} \mathrm{O}$ (75\%, 24.05 LAU), and $\mathrm{MeCN}(48 \%, 29.13$ LAU). 

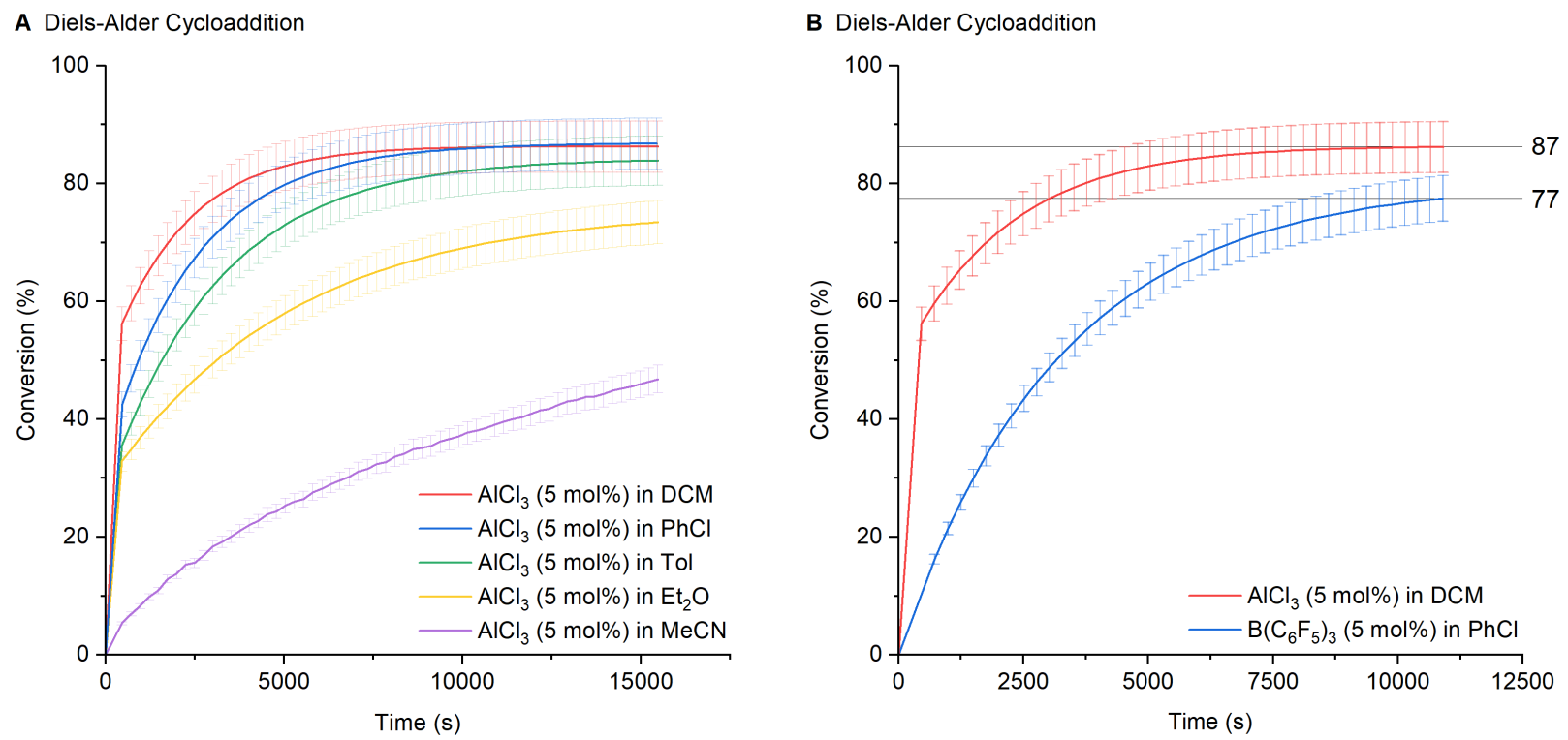

Figure 3. Product conversion for the Diels-Alder cycloaddition over time; (A) Reaction progress of $\mathrm{AlCl}_{3}$ in varying polar solvents, (B) $\mathrm{AlCl}_{3}$ vs. $\mathrm{B}\left(\mathrm{C}_{6} \mathrm{~F}_{5}\right)_{3}$ catalysis with similar $\mathrm{LAU}$ values.

Interestingly, the expected trend did not quite match for $\mathrm{AlCl}_{3}$ in acetonitrile. When comparing the product conversion in the catalytic reaction to the LAU values in the FLA method, $\mathrm{AlCl}_{3}$ in acetonitrile demonstrated a moderate LAU value (29.13), almost equivalent to toluene (28.89), while the Diels-Alder cycloaddition yielded a slower and lower product conversion (48\% for acetonitrile and $84 \%$ for toluene). The slight difference seen in the rate of the chemical reaction and the $\mathrm{LAU}$ value for $\mathrm{AlCl}_{3}$ in acetonitrile may be the result of predominant formation of solvated, monomeric $\mathrm{AlCl}_{3}$, and the absence of other reactive species such as aggregates and mixed salt species. $^{20}$

The FLA method affords a measure of the linear combination of all possible states of Lewis acid in solution, and therefore incorporates the potential mixture of solvents into the LAU value, to represent the effective strength of the Lewis acid solution in application. While the FLA method can measure the averaged LAU value of all active Lewis acid species in solution, the catalytic 
reaction only accounts for the product conversion utilizing the free Lewis acid over a certain period. By employing a more polar coordinating solvent, such as acetonitrile, the Lewis acid catalyst may be more prone to generate solvates, resulting in a lower amount of free Lewis acid being used to catalysis the reaction, thus leading to a slower reaction rate demonstrated by a lower product conversion.

To ensure the observed trends in $\mathrm{AlCl}_{3}$ were not simply the result of the Lewis acid chosen, but instead a direct correlation to the FLA method, we explored the five other Lewis acids, $\mathrm{B}\left(\mathrm{C}_{6} \mathrm{~F}_{5}\right)_{3}$, $\mathrm{B}\left(2,4,6-\mathrm{C}_{6} \mathrm{~F}_{3} \mathrm{H}_{2}\right)_{3}, \mathrm{In}(\mathrm{OTf})_{3}, \mathrm{Sc}(\mathrm{OTf})_{3}$, and $\mathrm{Zn}(\mathrm{OTf})_{2}$ as catalysts under the same conditions. For $\mathrm{B}\left(\mathrm{C}_{6} \mathrm{~F}_{5}\right)_{3}$ and $\mathrm{B}\left(2,4,6-\mathrm{C}_{6} \mathrm{~F}_{3} \mathrm{H}_{2}\right)_{3}$ (Figure $\left.\mathbf{S 1 3 4}\right)$ the same trends as for $\mathrm{AlCl}_{3}$ were observed. Both the LAU values and the percent yield of product conversion in the Diels-Alder cycloaddition increased by solvent polarity and were lowered by donor ability; $\mathrm{B}\left(\mathrm{C}_{6} \mathrm{~F}_{5}\right)_{3}$ : $\mathrm{DCM}(87 \%, 37.10$ LAU), $\mathrm{PhCl}(83 \%, 35.88 \mathrm{LAU})$, Tol (80\%, $30.25 \mathrm{LAU}), \mathrm{Et}_{2} \mathrm{O}(72 \%, 26.50 \mathrm{LAU})$ and $\mathrm{B}(2,4,6-$ $\left.\mathrm{C}_{6} \mathrm{~F}_{3} \mathrm{H}_{2}\right)_{3}: \mathrm{DCM}(20 \%, 32.71 \mathrm{LAU}), \mathrm{PhCl}(11 \%, 31.76 \mathrm{LAU}), \mathrm{Tol}(9 \%, 25.84 \mathrm{LAU}), \mathrm{Et}_{2} \mathrm{O}$ (6\%, 22.36 LAU).

Interestingly, the trend also holds for $\operatorname{In}(\mathrm{OTf})_{3}$, despite undergoing a retro Diels-Alder cycloaddition (rDA) (Figure S133); $\operatorname{In}(\mathrm{OTf})_{3}$ is known to be a chemical activator for $\mathrm{rDA}$ reactions with certain dienes and dienophiles ${ }^{40}$ However, for $\mathrm{Sc}(\mathrm{OTf})_{3}$, the reverse general trend was observed (Figure S133); higher product conversion was seen in stronger coordinating solvents, however, the LAU values did not correlate to product conversion. The results are as followed, $\mathrm{Sc}(\mathrm{OTf})_{3}: \mathrm{MeCN}(41 \%, 29.05 \mathrm{LAU}), \mathrm{Et}_{2} \mathrm{O}(25 \%, 25.32 \mathrm{LAU}), \mathrm{PhCl}(21 \%, 31.14 \mathrm{LAU})$, Tol $(16 \%, 30.37 \mathrm{LAU})$, and DCM $(10 \%, 33.09 \mathrm{LAU})$. This is likely due to $\mathrm{Sc}(\mathrm{OTf})_{3}$ losing a triflate moiety in coordinating solvents, en route to a stronger, cationic species that possibly remains coordinated to the product, de facto poisoning the catalyst. ${ }^{35}$ Unfortunately, we were 
unable to make any comparisons with $\mathrm{Zn}(\mathrm{OTf})_{2}$, as no product formation was observed in any of the solvents, likely due to both the insolubility and weak Lewis-acid strength of the zinc species. ${ }^{19}$

A clear correlation between the LAU values and the product yield for the Diels-Alder cycloaddition was observed with the neutral boranes, $\mathrm{AlCl}_{3}$, and $\operatorname{In}(\mathrm{OTf})_{3}$. By increasing the polarity of the solvent, both the LAU value and percent yield increased, whereas in the presence of a stronger donating solvent, a decrease in LAU value and percent yield was seen. In general, the results obtained from the Diels-Alder reactions support our initial solvation studies, suggesting that the FLA method can accurately correlate LAU values to the solvent impact of catalytic activity.

We then investigated the hydrosilylation (Table S9) of benzophenone (12) with triethylsilane (13) as the chosen substrate combination toward triethyl(1,1-diphenylmethoxy)silane (14). For $\mathrm{B}\left(\mathrm{C}_{6} \mathrm{~F}_{5}\right)_{3}$ and $\mathrm{B}\left(2,4,6-\mathrm{C}_{6} \mathrm{~F}_{3} \mathrm{H}_{2}\right)_{3}$, we observed similar results as seen in the Diels-Alder cycloaddition. The reaction progression varied significantly as a function of polarity and coordinating ability of the solvent (see Figure S136). On the other hand, we were unable to correlate our FLA method to "solution-state" measurements with the other four Lewis acids $\left(\mathrm{AlCl}_{3}\right.$, $\operatorname{In}(\mathrm{OTf})_{3}, \operatorname{Sc}(\mathrm{OTf})_{3}$, and $\left.\mathrm{Zn}(\mathrm{OTf})_{2}\right)$. The latter is not surprising given the well-established mechanism of borane-catalyzed hydrosilylation and the fact that these Lewis acids are generally not known to catalyze this reaction, anyway ${ }^{39,41}$

The results obtained with the neutral boranes support our initial solvation studies and demonstrate that the solvent effect generally follows the impact measured by the FLA method (i.e., the LAU value). Thus, for a better, more solid comparison of Lewis acids, the following neutral boranes were applied in the reaction monitoring (Figure 5 and Table $\mathbf{S 1}$ ): $\mathrm{B}\left(\mathrm{C}_{6} \mathrm{~F}_{5}\right)_{3}, \mathrm{~B}\left(p-\mathrm{C}_{6} \mathrm{~F}_{4} \mathrm{H}\right)_{3}$, 
$\mathrm{B}\left(2,4,6-\mathrm{C}_{6} \mathrm{~F}_{3} \mathrm{H}_{2}\right)_{3}, \mathrm{~B}\left(3,4-\mathrm{C}_{6} \mathrm{~F}_{2} \mathrm{H}_{3}\right)_{3}$ and $\mathrm{B}\left(4-\mathrm{C}_{6} \mathrm{FH}_{4}\right)_{3}$. As reported in the literature, the number and positioning of the fluorine substituents on the arylboranes have noticeable effects on Lewis acidity. Illustrated in our most recent paper, ${ }^{20}$ the LAU values measured in toluene correlate well with the reported literature trends for Lewis acidity: $\mathrm{B}\left(4-\mathrm{C}_{6} \mathrm{FH}_{4}\right)_{3}$ (LAU: 25.32$)<\mathrm{B}\left(2,4,6-\mathrm{C}_{6} \mathrm{~F}_{3} \mathrm{H}_{2}\right)_{3}(\mathrm{LAU}$ : $25.84)<\mathrm{B}\left(3,4-\mathrm{C}_{6} \mathrm{~F}_{2} \mathrm{H}_{3}\right)_{3}(\mathrm{LAU}: 26.41)<\mathrm{B}\left(p-\mathrm{C}_{6} \mathrm{~F}_{4} \mathrm{H}\right)_{3}(\mathrm{LAU}: 29.23)<\mathrm{B}\left(\mathrm{C}_{6} \mathrm{~F}_{5}\right)_{3}(\mathrm{LAU}: 30.25)$. When applied in a specific solvent, such as dichloromethane, chlorobenzene, or diethyl ether, the trend is the same as in toluene; the Lewis acid strength decreases in the following order: $\mathrm{B}\left(\mathrm{C}_{6} \mathrm{~F}_{5}\right)_{3}$ $>\mathrm{B}\left(p-\mathrm{C}_{6} \mathrm{~F}_{4} \mathrm{H}\right)_{3}>\mathrm{B}\left(2,4,6-\mathrm{C}_{6} \mathrm{~F}_{3} \mathrm{H}_{2}\right)_{3}>\mathrm{B}\left(3,4-\mathrm{C}_{6} \mathrm{~F}_{2} \mathrm{H}_{3}\right)_{3}>\mathrm{B}\left(4-\mathrm{C}_{6} \mathrm{FH}_{4}\right)_{3}$ regardless of the solvent utilized.

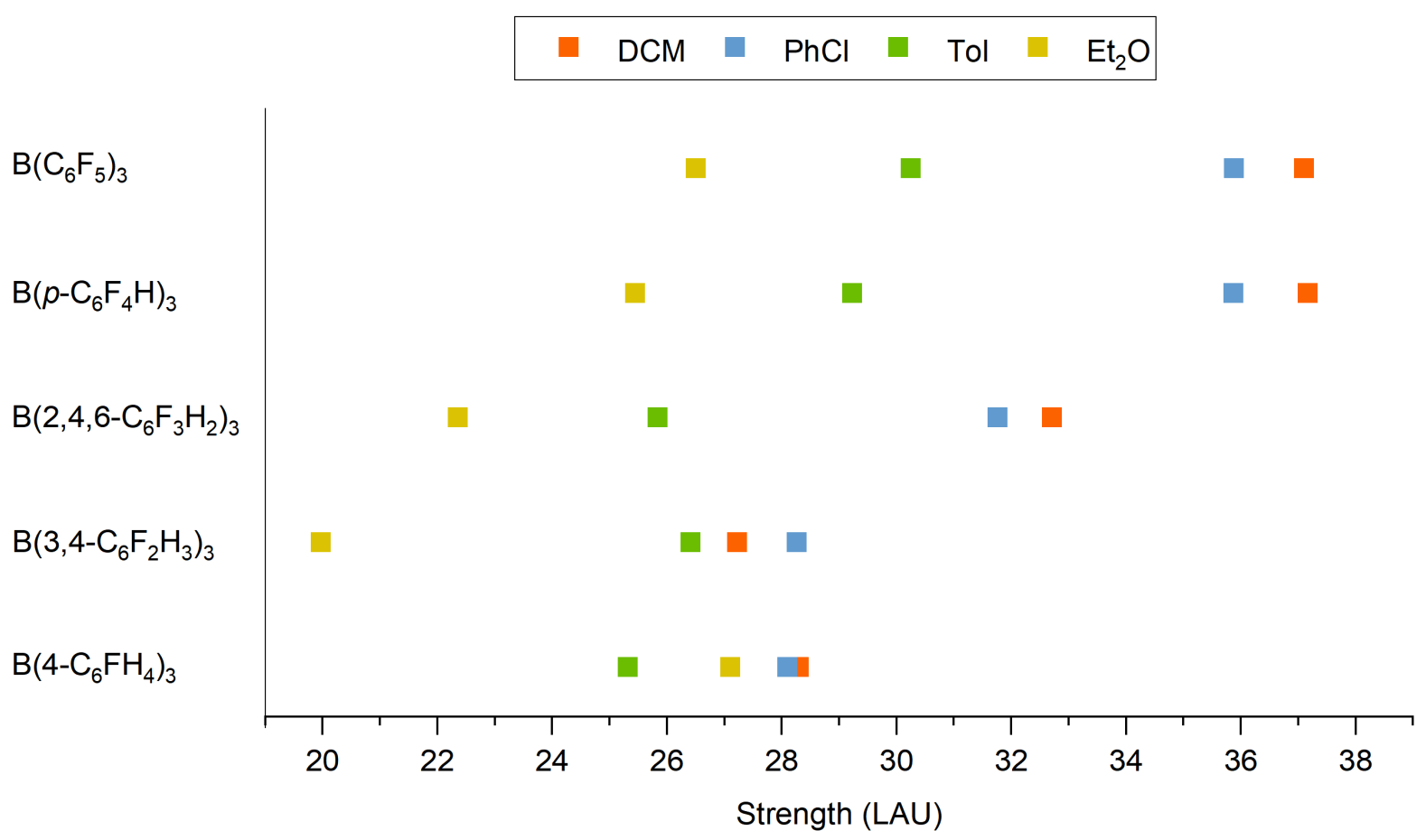

Figure 5. Lewis acidity scale measured in LAUs for following six Lewis acids: $\mathrm{B}\left(\mathrm{C}_{6} \mathrm{~F}_{5}\right)_{3}, \mathrm{~B}(p$ $\left.\mathrm{C}_{6} \mathrm{~F}_{4} \mathrm{H}\right)_{3}, \mathrm{~B}\left(2,4,6-\mathrm{C}_{6} \mathrm{~F}_{3} \mathrm{H}_{2}\right)_{3}, \mathrm{~B}\left(3,4-\mathrm{C}_{6} \mathrm{~F}_{2} \mathrm{H}_{3}\right)_{3}$ and $\mathrm{B}\left(4-\mathrm{C}_{6} \mathrm{FH}_{4}\right)_{3}$, in varying polar solvents. 
Even with the decrease in the overall Lewis acid strength of the various arylboranes, the trend seen previously with $\mathrm{B}\left(\mathrm{C}_{6} \mathrm{~F}_{5}\right)_{3}$ showcasing the dichotomy of polarity and donor ability of the solvent was observed in the various neutral boranes with the exception of $\mathrm{B}\left(4-\mathrm{C}_{6} \mathrm{FH}_{4}\right)_{3}$, due the formation of additional emissive species present in solution. ${ }^{20}$ For instance, $\mathrm{B}\left(\mathrm{C}_{6} \mathrm{~F}_{5}\right)_{3}$ had an LAU of 37.10 in DCM, 35.88 in $\mathrm{PhCl}, 30.25$ in Tol and 26.50 in $^{2} t_{2} \mathrm{O}$. The neutral boranes demonstrated higher LAU values in a more polar solvent, such as dichloromethane, compared to a less polar solvent, like toluene, whereas the LAU values decreased in the presence of a more coordinating solvent, like diethyl ether, compared to a non-coordinating solvent, such as toluene. A clear correlation in LAU strength and solvent was seen with the neutral boranes, following in a decreasing order of $\mathrm{DCM}>\mathrm{PhCl}>\mathrm{Tol}>\mathrm{Et}_{2} \mathrm{O}$.

Taken altogether, when applied to the Diels-Alder cycloaddition and hydrosilylation reactions, the LAU values proved to be consistent with the catalytic application of the Lewis acids in the respective solvents. For example, when monitoring the reaction progress of $\mathrm{B}\left(p-\mathrm{C}_{6} \mathrm{~F}_{4} \mathrm{H}\right)_{3}$ in the Diels-Alder cycloaddition and hydrosilylation reactions in the various solvents, we observed higher product conversion in solvents with increased polarity, and slower product formation with stronger coordinating solvents, shown in Figure 6. This trend holds consistently across the borane series while in the same solvent (Figure S135 and S137): Slower reactions where a lower LAU value was measured, typically in more coordinating solvents, and faster reactions where higher LAU values were measured, with less coordinating, but more polar solvents (see Figures S134 and Figures S136). 
A Diels-Alder Cycloaddition

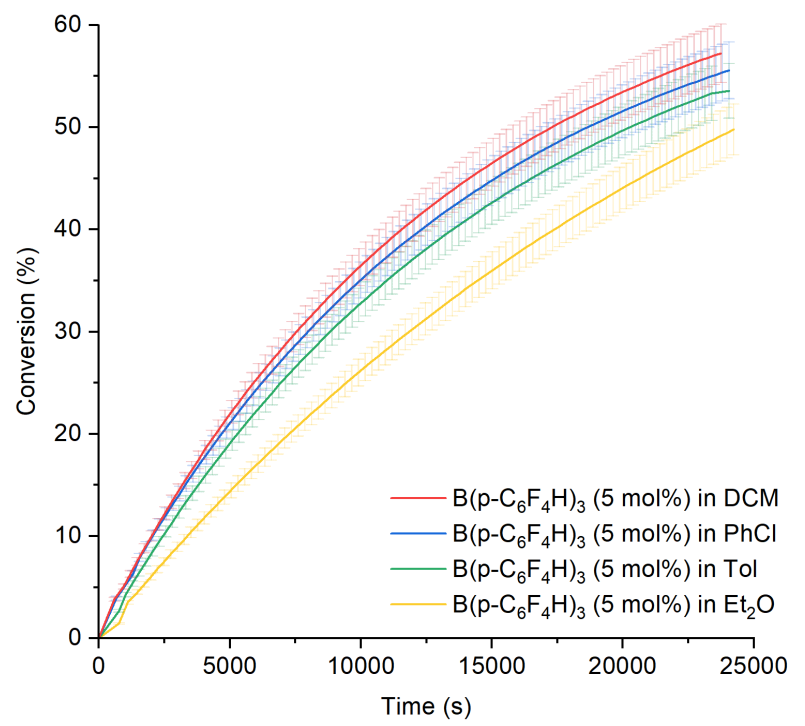

B Hydrosilylation

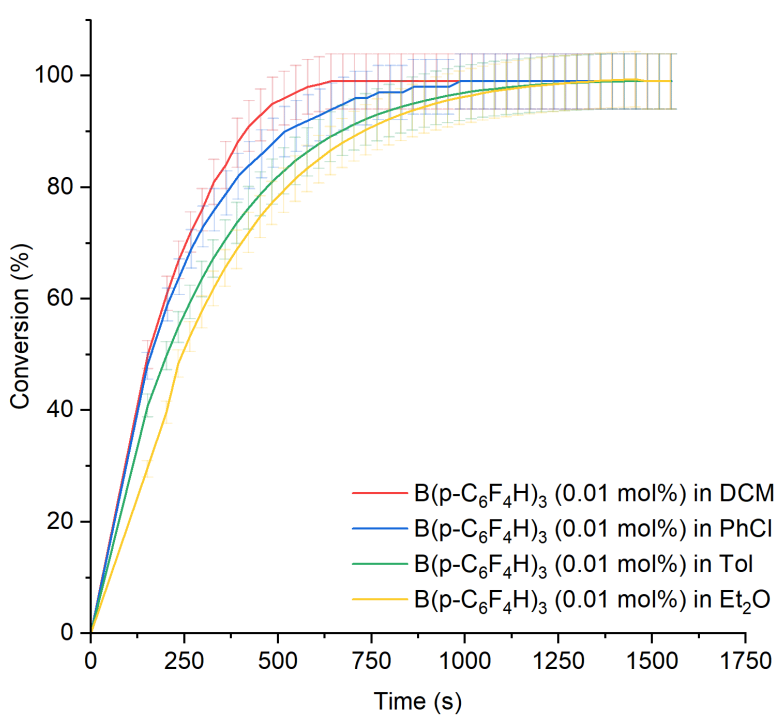

Figure 6. Product conversion in percent yield over time for the Diels-Alder cycloaddition (A) and hydrosilylation (B) of $\mathrm{B}\left(p-\mathrm{C}_{6} \mathrm{~F}_{4} \mathrm{H}\right)_{3}$ in varying polar solvents.

Taking this into consideration, we sought to determine if an LAU value was universal, or in other words, does an LAU value for one Lewis acid in one solvent result in the same catalytic response as a different Lewis acid in a different solvent with the same LAU value. To probe this correlation, Lewis acids with similar LAU values were analyzed. We selected $\mathrm{AlCl}_{3}$ in $\mathrm{DCM}$ (36.1 $\mathrm{LAU})$ and $\mathrm{B}\left(\mathrm{C}_{6} \mathrm{~F}_{5}\right)_{3}$ in $\mathrm{PhCl}(35.9 \mathrm{LAU})$. Both Lewis acids are considered relatively strong, based on other methodologies ${ }^{42,43}$ and the FLA scale. ${ }^{19,20}$ For our initial efforts, we focused on the DielsAlder cycloaddition and observed after 4 hours an $87 \%$ yield for $\mathrm{AlCl}_{3}$ in $\mathrm{DCM}$ and a $77 \%$ yield for $\mathrm{B}\left(\mathrm{C}_{6} \mathrm{~F}_{5}\right)_{3}$ in $\mathrm{PhCl}$, (see Table S8 and Figure 3B). Despite nearly identical LAU measurements (difference of $1 \%$ ), a $10 \%$ increase in product yield was observed. The $1 \%$ difference in LAU value is within the margin of error for the FLA method (a 0.25 LAU has previously been established as a generalized over-estimation of the appropriate error for the measurement). ${ }^{20} \mathrm{By}$ comparison, the variance in the product yield of the catalytic reactions across multiple runs was 
$8.5 \%$, placing the change in yield nearly within the margin of error. Since, the LAU scale is nonlinear, as it is based on a parabola, the magnitude of the difference between two values increases as the LAU value increases. This encouraging result suggests that the LAU values may be readable across the periodic table. At this point, it is still vital to note that catalytic ability of Lewis acids is not strictly due strength alone, but other parameters such as solvent polarity and their donor ability needs to be considered. The significant studies required to elucidate this are on-going and we hope to report these results in due course.

\section{CONCLUSION}

In conclusion, we have demonstrated the impact of solvent on the FLA method and provided insight into predicting chemical reactivity. Two significant factors influencing the measured Lewis acidity in the FLA method is the polarity and donating potential of the solvent. In the presence of a more polar non-coordinating solvent, we observed higher LAU values compared to a less polar coordinating solvent. This trend generally holds true across varied Lewis acids and proves to be the case when measuring the catalytic ability of these species in varying solvents. Since, the FLA method is based on the binding affinity of a Lewis acid to a specific theoretical Lewis base in a particular solvent, we observed the binding of the free Lewis acid to the Lewis base probe. However, depending on the coordinating ability of the solvent, a complex equilibrium may be observed. This was specifically seen in the titration data with diethyl ether and a strong Lewis acid. Two equilibria are present, and we hypothesize that the first equilibrium involves the free-Lewis acid, and the second equilibrium the solvated Lewis acid. This likely occurs in any donating solvent but was not always strictly separable in our measurements. In addition, the dichotomy seen in the FLA method can be observed in the chemical reactions conducted. As a result of the solutionstate nature of the FLA methodology, we were able to provide insight into the effectiveness of 
these Lewis acids in specific reaction environments and demonstrate through reaction monitoring a correlation that coordinates the FLA measurement directly to catalytic reactions.

Although, the LAU scale in the FLA method correlated quite well when discussing catalytic efficiency of Lewis acids, there currently remains limitations to the method for it to be able to be truly predictive. While our method can be used to observe competing equilibria caused by solvation of a Lewis acid, and be used to discuss that effect on catalysts activity, it is limited strictly to binding of the Lewis acid, and not unbinding, which is vital in understanding how different Lewis acids behave differently in a catalytic environment, such as that using $\operatorname{Sc}(\mathrm{OTf})_{3}$. Additionally, the method cannot account for deviating reaction mechanisms; for example the hydrosilylation of benzophenone is known to proceed using boranes, however, it is ineffective with other Lewis acids such as $\mathrm{AlCl}_{3}, \operatorname{In}(\mathrm{OTf})_{3}, \operatorname{Sc}(\mathrm{OTf})_{3}$ or $\mathrm{Zn}(\mathrm{OTf})_{2}$. This could only be predicted from prerequisite knowledge of the limitations of the reaction being performed and cannot be predicted by Lewis-acid strength alone. Nonetheless, the results of the binding of a Lewis acid, even as impacted by solvent, via both polarity and donor potential, and solvation can be appropriately gauged by the LAU value determined from the FLA method. To continue advancing the FLA approach into a more robust and practical method that can be used to predict chemical reactivity, we are further investigating approaches to measuring such discrepancies. We are confident that the insights obtained in our study so far will further our understanding in predicting Lewis-acid reactivity and advancing the design and development of selective transformations relying on readily available Lewis-acid catalysts. 


\section{ASSOCIATED CONTENT}

\section{Supporting Information.}

Experimental details, chromaticity data of all FLAs, emission and excitation data of all FLAs, catalytic reaction details and rate constants can be found in the Supporting Information online at

\section{AUTHOR INFORMATION}

\section{Corresponding Author}

*Email: tbaumgar@yorku.ca, caputo@yorku.ca

\section{Author Contributions}

The manuscript was written through contributions of all authors. All authors have given approval to the final version of the manuscript.

\section{Notes}

The authors declare no competing financial interest.

\section{ACKNOWLEDGMENT}

We are grateful to the Natural Sciences and Engineering Research Council of Canada, the Canada Foundation for Innovation, and the Canada Research Chairs program. Thanks to Dr. Howard Hunter (York University) for NMR spectroscopy support.

\section{ABBREVIATIONS}

FLP, frustrated Lewis pair; FLA, fluorescent Lewis adduct; CIE, commission international de l'éclairage; LAU, Lewis acid unit; rDA, retro Diels-Alder cycloaddition. 


\section{REFERENCES}

1. Yamamoto, H. Lewis Acids in Organic Synthesis. Wiley-VCH Verlag, 2008.

2. Stephan, D. W. The Broadening Reach of Frustrated Lewis Pair Chemistry. Science. 2016, 354, aaf7229.

3. Corma, A.; Garcia, H. Lewis Acids: From Conventional Homogeneous to Green Homogeneous and Heterogeneous Catalysis. Chem. Rev. 2003, 103, 4307-4366.

4. Jäkle, F. Advances in the synthesis of organoborane polymers for optical, electronic, and sensory applications. Chem. Rev. 2010, 110, 3985-4022.

5. Bridges, C. R.; Baumgartner, T. Lewis acids and bases as molecular dopants for organic semiconductors. J. Phys. Org. Chem. 2020, 33, 4077.

6. Baumgartner, T.; Jäkle, F. Main Group Strategies towards Functional Hybrid Materials. Wiley 2017.

7. Stephan, D.W., and Erker, G. Frustrated Lewis pair chemistry: development and perspectives. Angew. Chem. Int. Ed. Engl. 2015, 54, 6400-6441.

8. Légaré, M. A.; Courtemanche, M. A.; Rochette, É.; Fontaine, F. G. Metal-Free Catalytic C-H Bond Activation and Borylation of Heteroarenes. Science 2015, 349, 513-516.

9. Oestreich, M.; Hermeke, J.; Mohr, J. A Unified Survey of Si-H and H-H Bond Activation Catalysed by Electron-Deficient Boranes. Chem. Soc. Rev. 2015, 44, 2202-2220.

10. Carlson, R.; Lundstedt, T.; Nordahl, Å.; Prochazka, M. Lewis Acids in Organic Synthesis. Approach to a Selection Strategy for Screening Experiments. Acta Chem. Scand., Ser. B 1986, 40, 522-533.

11. Jensen, W. B. The Lewis Acid-Base Definitions; a Status Report. Chem. Rev. 1978, 78, $1-22$.

12. Murray, P. M.; Tyler, S. N. G.; Moseley, J. D. Beyond the Numbers: Charting Chemical Reaction Space. Org. Process Res. Dev. 2013, 17, 40-46.

13. Laszlo, P.; Teston, M. Determination of the Acidity of Lewis Acids. J. Am. Chem. Soc. 1990, 112, 8750-8754.

14. Beckett, M. A.; Strickland, G. C.; Holland, J. R.; Varma, K. S. A Convenient n.m.r. Method for the Measurement of Lewis Acidity at Boron Centres: Correlation of Reaction Rates of Lewis Acid Initiated Epoxide Polymerizations with Lewis Acidity. Polymer 1996, 37, 4629-4631.

15. Mayer, U.; Gutmann, V.; Gerger, W. The Acceptor Number - A Quantitative Empirical Parameter for the Electrophilic Properties of Solvents. Monatshefte Chem. 1975, 106, $1235-1257$.

16. Hilt, G.; Nödling, A. The Correlation of Lewis Acidities of Silyl Triflates with Reaction Rates of Catalyzed Diels-Alder Reactions. Eur. J. Org. Chem. 2011, 7071-7075.

17. Brown, I. D.; Skowron, A. Electronegativity and Lewis Acid Strength. J. Am. Chem. Soc. 1990, 112, 3401-3403.

18. Jupp, A. R.; Johnstone, T. C.; Stephan, D. W. The Global Electrophilicity Index as a Metric for Lewis Acidity. Dalton Trans. 2018, 47, 7029-7035.

19. Gaffen, J. R.; Bentley, J. N.; Torres, L. C.; Chu, C.; Baumgartner, T.; Caputo, C. B. A Simple and Effective Method of Determining Lewis Acidity by Using Fluorescence. Chem 2019, 5, 1567-1583. 
20. Bentley, J. N.; Elgadi, S. A.; Gaffen, J. R.; Demay-Drouhard, P.; Baumgartner, T.; Caputo, C. B. Fluorescent Lewis Adducts: A Pratical Guide to Relative Lewis Acidity. Organometallics 2020, 39, 3645-3655.

21. Baumgartner, T.; Neumann, T.; Wirges, B. The Dithieno[3,2-b:2',3'-d]phosphole System: A Novel Building Block for Highly Luminescent $\pi$-Conjugated Materials. Angew. Chem. Int. Ed. 2004, 45, 6197-6201.

22. Baumgartner, T.; Bergmans, W.; Kárpáti, T.; Neumann, T.; Nieger, M.; Nyulászi, L. From Model Compounds to Extended $\pi$-Conjugated Systems: Synthesis and Properties of Dithieno[3,2-b:2',3'-d]phospholes. Chem. Eur. J. 2005, 11, 4687-4699.

23. Dienes, Y.; Durben, S.; Kárpáti, T.; Neumann, T.; Englert, U.; Nyulászi, L.; Baumgartner, T. Selective Tuning of the Band Gap of $\pi$-Conjugated Dithieno[3,2-b:2',3'd]phospholes toward Different Emission Colors. Chem. Eur. J. 2007, 13, 7487-7500.

24. Baumgartner, T. Insights on the Design and Electron-Acceptor Properties of Conjugated Organophosphorus Materials. Acc. Chem. Res. 2014, 47, 1613-1622.

25. Hilt, G.; Pünner, F.; Möbus, J.; Naseri, V.; Bohn, M. A. A Lewis Acidity Scale in Relation to Rate Constants of Lewis Acid Catalyzed Organic Reactions. Eur. J. Org. Chem. 2011, 30, 5962-5966.

26. Kang, H.; Zhou, B.; Li, M.; Xue, X.-S.; Cheng, J.-P. Quantification of the Activation Capabilities of Lewis/Bronsted Acid for Electrophilic Trifluoromethylthiolating Reagents. Chin. J. Chem. 2020, 38, 130-134.

27. Reichardt, C. Empirical Parameters of Solvent Polarity as Linear Free-Energy Relationships. Angew. Chem. Int. Ed. Engl. 1979, 18, 98-110.

28. Shcherbina, N. A.; Pomogaeva, A. V.; Lisovenko, A. S.; Kazakov, I. V.; Gugin, N. Y.; Khoroshilova, O.V.; Kondrat'ev, Y. V.; Timoshkin, A. Y. Structures and Stability of Complexes of $\mathrm{E}_{(}\left(\mathrm{C}_{6} \mathrm{~F}_{5}\right)_{3}(\mathrm{E}=\mathrm{B}, \mathrm{Al}, \mathrm{Ga}, \mathrm{In})$ with Acetonitrile. Z. Anorg. Allg. Chem. 2020, $646,873-881$.

29. Gutmann V. Empirical Parameters for Donor and Acceptor Properties of Solvents. Electrochim. Acta 1976, 21, 661-670.

30. Lakowicz, J.R. Principles of Fluorescence Spectroscopy, Third Edition Springer, 2006

31. Mayer, R. J.; Hampel, N.; Ofial, A. R. Lewis Acidic Boranes, Lewis Bases, and Equilibrium Constants: A Reliable Scaffold for a Quantitative Lewis Acidity/Basicity Scale. Chem. Eur. J. 2021, 27, 4070-4080.

32. Lawson, J. R.; Wilkins, L. C.; Melen, R. L. Tris(2,4,6-Trifluorophenyl)Borane: An Efficient Hydroboration Catalyst. Chem. Eur. J. 2017, 23, 10997-11000.

33. Sivaev, I. B.; Bregadze, V. I. Lewis Acidity of Boron Compounds. Coord. Chem. Rev. 2014, 270-271, 75-88.

34. Hog, M.; Schneider, M.; Studer, G.; Bäuerle, M.; Föhrenbacher, S. A.; Scherer, H.; Krossing, I. An Investigation of the Symmetric and Asymmetric Cleavage Products in the System Aluminum Trihalide/1-Butylimidazole. Chem. Eur. J. 2017, 23, 11054-11066.

35. Kobayashi, S. Scandium Triflate in Organic Synthesis. Eur. J. Org. Chem. 1999, 1, 1527.

36. Iacobucci, C.; Jouini, N.; Massi, L.; Olivero, S.; De Angelis, F.; Duñach, E.; Gal, J.-F. Quantitative ligand affinity scales for metal triflate salts: application to isomer differentiation. ChemPlusChem 2017, 82, 498-506. 
37. Krygowski, T. M.; Fawcett. W. R. Complementary Lewis Acid-Base description of Solvent Effects. I. Ion-Ion and Ion-Dipole Interactions. J. Am. Chem. Soc. 1975, 97, 2143-2148.

38. Vermeern, P.; Tiezza, M. D.; Dongen, M. V.; Fernández, I.; Bickelhaupt, F. M.; Hamlin, T. A. Lewis Acid-Catalyzed Diels-Alder Reactions: Reactivity Trends across Periodic Table. Chem. Eur. J. 2021, 27.

39. Bach, P.; Albright, A.; Laali, K.K. Influence of Lewis Acid and solvent in the Hydrosilylation of Aldehydes and Ketones with Et3SiH; Tris(pentafluorophenyl)borane $\mathrm{B}\left(\mathrm{C}_{6} \mathrm{~F}_{5}\right)_{3}$ versus Metal Triflates $\left[\mathrm{M}(\mathrm{OTf})_{3} ; \mathrm{M}=\mathrm{Sc}, \mathrm{Bi}, \mathrm{Ga}\right.$, and $\left.\mathrm{Al}\right]-$ Mechanistic Implications. Eur. J. Org. Chem. 2009, 1961-1966.

40. Rickborn, B. The Retro-Diels-Alder Reaction Part I. C-C Dienophiles. Wiley, 2004.

41. Parks, D. J.; Piers, W. E. Tris(pentafluorophenyl)boron-Catalyzed Hydrosilylation of Aromatic Aldehydes, Ketones, and Esters. J. Am. Chem. Soc. 1996, 118, 9440-9441.

42. Prajapati, A.; Kumar, M.; Thakuria, R.; Basak, A.K. In( $(\mathrm{OTf})_{3}$ catalyzed reductive etherification of 2-aryloxybenzaldehydes and 2-(arylthiol)benzaldehydes. Tet. Lett. 2019, 60, 150955.

43. Müller, L.O., Himmel, D., Stauffer, J., Steinfeld, G., Slattery, J., Santiso-Quiñones, G., Brecht, V., and Krossing, I. Simple access to the non-oxidizing Lewis superacid $\mathrm{PhF} / \mathrm{Al}(\mathrm{ORF})_{3}\left(\mathrm{RF}=\mathrm{C}\left(\mathrm{CF}_{3}\right)_{3}\right)$. Angew. Chem. Int. Ed. 2008, 47, 7659-7663.

\section{TABLE OF CONTENTS}

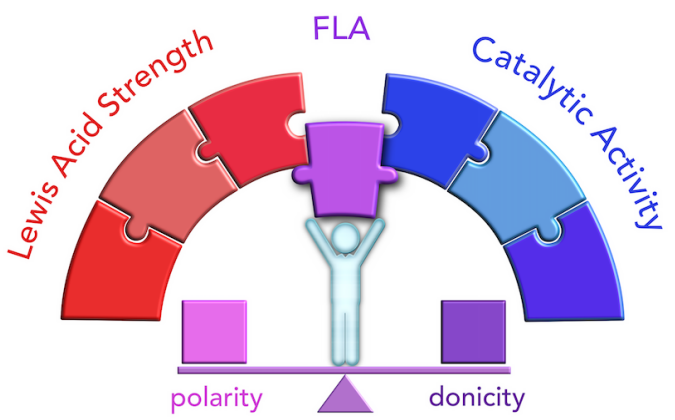

